\title{
Suggestions for Learning Hawaiian
}

The objectives of the Hawaiian course are: (1) ability to speak and (2) ability to read.

Learning to speak is often called the oral-aural approach to language learning. This is because speaking (oral) also involves understanding what is heard (aural). Learning to speak first demands mastery of the new melody and the new sounds. Hawaiian melody is not like English melody. There are fewer ups and downs in pitch, fewer variations in stress levels, and often there is a slight rise before a pause. Proper melody and speed are even more important than good pronunciation of individual sounds. If the melody and speed sound Hawaiian, slight mispronunciation of individual sounds will not be noticed. The difficult sounds in Hawaiian include the "pure" vowels (without accompanying glides), the only slightly aspirated $p$ and $k$, and the glottal stop.

Understanding comes from hearing Hawaiian. For this the laboratory is supremely helpful, as is every opportunity that can be found to practice with Hawaiian speakers and with fellow students. The student is to mimic the tapes and the Hawaiian he hears. Local persons will have little difficulty, but mainland-reared students will have to break with many English habits.

The patterns that constitute the language must be memorized, the dialogues repeated-out loud-until they can be reproduced flawlessly and effortlessly. We admire the skill of a tennis player who seems to perform without effort. First attempts of even brilliant students at dialogue are halting, but with repetition comes ease and finally a nativelike sound.

The keynote to success is participation. You do not learn to swim by reading about it in a book or by wishful thinking, but by getting into the water. Any skill comes after practice and involvement. And so with language learning.

Learning to read Hawaiian is easy for one learning to speak. Because the writing largely follows the sounds there is no difficult alphabet to learn.

Here are some study suggestions.

Any fear of public display is fatal. Verbosity, use of clichés and banalities, exhibitionism, and other traits that you may ordinarily deplore are invaluable in attaining fluency. Shyness and pride must be overcome; 


\section{SUGGESTIONS FOR LEARNING HAWAIIAN}

one must not mind making mistakes or showing ignorance. Scoffers eventually respect intelligent perseverance.

Babble to yourself in Hawaiian. Put even the most banal thoughts into Hawaiian. Do not translate them from English into Hawaiian. Think in Hawaiian. Use tried-and-true patterns.

Speak Hawaiian with your classmates, outside of class as well as in. This gives you oral training and ear training. Hawaiian can be a "fun language" that your outside friends will not understand, and that you may prefer to use on a telephone party line.

Space your homework, laboratory hours, and classes. Thirty minutes' study a day is more effective than an hour every other day, but snatches of conversation several times every day with deliberate application of new patterns is better still. The least effective procedure is postponing study and cramming before examinations. Such foolish techniques make little provision for oral training and none at all for ear training.

Keep up with the class. If you fall behind you will be uncomfortable and will hold back the entire class.

Writing out Hawaiian is a good aid to memory. Vocabulary cards, with the Hawaiian phrase or sentence on one side of the card and an English translation on the other, speed up learning. Carry these cards or slips around with you. Study the as-yet-unmastered phrases several times a day, while riding the bus, eating, or even while brushing your teeth. Above all, learn the new words in phrases and sentences, not in isolation.

Review unceasingly.

Three ways in which Hawaiian differs from English cause special difficulties: (1) A common word order is VERB plus SUBJECT plus OBJECT. (2) Adjectives follow nouns. (3) Abstract and frequently mass nouns take articles (the beauty, the God, the Sunday, the school). Concentrate on these special difficulties.

A language is a set of habits. Habits are acquired by repetition. Language learning is repetition. It is not intellectual but muscular. Repeat and repeat. The only key to success is overlearning. If you speak a word four times on four occasions, and hear it on four occasions, it is usually mastered.

May this be true of your Hawaiian: I will be METICULOUS yet GARRULOUS.

Here is your first lesson in Hawaiian:

'A'a $i$ ka hula. Waiho i ka hilahila

$i$ ka hale.

E kaupẽ aku no $i$ ka hoe, e kö

mai $i$ ka hoe, e hoe.
Dare to dance. Leave embarrassment at home.

Put forward the paddle, draw the paddle toward you, paddle. 